\title{
Cracking Tendency Prediction of High-Performance Cementitious Materials
}

\author{
Ke Chen, ${ }^{1}$ Hui Hu, ${ }^{1}$ Ke Chen, ${ }^{2}$ Zhaohui Chen, ${ }^{1}$ and Xin Wang ${ }^{2}$ \\ ${ }^{1}$ Key Laboratory of New Technology for Construction of Cities in Mountain Area, Chongqing University, \\ Ministry of Education, Chongqing 400044, China \\ ${ }^{2}$ School of Materials Science and Engineering, Chongqing University, Chongqing 400044, China \\ Correspondence should be addressed to Ke Chen; kechen@cqu.edu.cn and Zhaohui Chen; czh1222@163.com
}

Received 31 October 2013; Revised 20 February 2014; Accepted 28 May 2014; Published 5 August 2014

Academic Editor: Daniel Balint

Copyright (C) $2014 \mathrm{Ke}$ Chen et al. This is an open access article distributed under the Creative Commons Attribution License, which permits unrestricted use, distribution, and reproduction in any medium, provided the original work is properly cited.

\begin{abstract}
The constraint ring test is widely used to assess the cracking potential for early-age cementitious materials. In this paper, the analytical expressions based on elastic mechanism are presented to estimate the residual stresses of the restrained mortar ring by considering the comprehensive effects of hydration heat, autogenous and drying shrinkage, creeping, and restraint. In the present analytical method, the stress field of the restrained ring is treated as the superposition of those caused by hydration heat, external restraint, autogenous and drying shrinkage, and creep. The factors including the properties of materials, environmental parameters such as relative humidity and temperature, the geometry effect of specimen, and the relative constraint effects of steel ring to mortar ring, are taken into account to predict the strain development with age of mortar. The temperature of the ring, the elastic modulus, the creep strain, and the split tensile strength are measured to validate the model. The age of cracking is predicted by comparing the estimated maximum tensile stress of the restrained mortar ring with the measured split tensile strength of specimen. The suitability of the present analytical method is assessed by comparing with the restraint ring test and a soundly good agreement is observed.
\end{abstract}

\section{Introduction}

Early-age cracking of cementitious materials has driven great deal of research interests in recent years owing to its contributions in several aspects: the appreciation to the durability issues where cracking plays a dominant role, the advent of high-performance concretes with low water/cement $(\mathrm{w} / \mathrm{c})$ ratio which is much more prone to cracking, and the need for rehabilitation and repairing systems which is sensitive to cracks $[1-3]$.

The cementitious materials change volume tremendously in the early-age due to the variations of moisture and temperature, and the chemical reaction. If restrained, these volumetric changes would result in residual stress development that can lead to cracking [4]. The restrained ring test has recently become a well-accepted method to assess a mixture's susceptibility to restrained shrinkage cracking [57]. Among the research efforts, early-age cracking has been mainly evaluated by qualitative means, which are useful for comparing the sensitivity to cracking of different mixes and additives used to reduce cracking. However, they are not sufficient for a study of the mechanisms involved, which is an essential step towards developing new strategies and products to harness early-age cracking $[8,9]$.

According to the qualitative cracking tests, a variety of factors are shown to be significant to the early-age cracking. In high-performance/high strength concrete of low w/c ratio, the early-age cracking can be due to three processes occurring simultaneously, which are shrinkage (i.e., autogenous shrinkage and drying shrinkage), hydrate heat development, and stress relaxation. In addition, whether the cracking occurs or not is dependent also on the restraint, which exists in the concrete mixtures due to the aggregates and reinforcement and has influence on the strain creep and stress relaxation [2]. Therefore, an analytical expression is present in this paper, in order to estimate the residual stresses of the mortar ring restrained by a steel ring (imitating the restraint efforts in the concrete by aggregates, reinforcement, and so on) by taking into account the comprehensive effects due to hydration heat, autogenous and drying shrinkage, restraint effects, and creep 


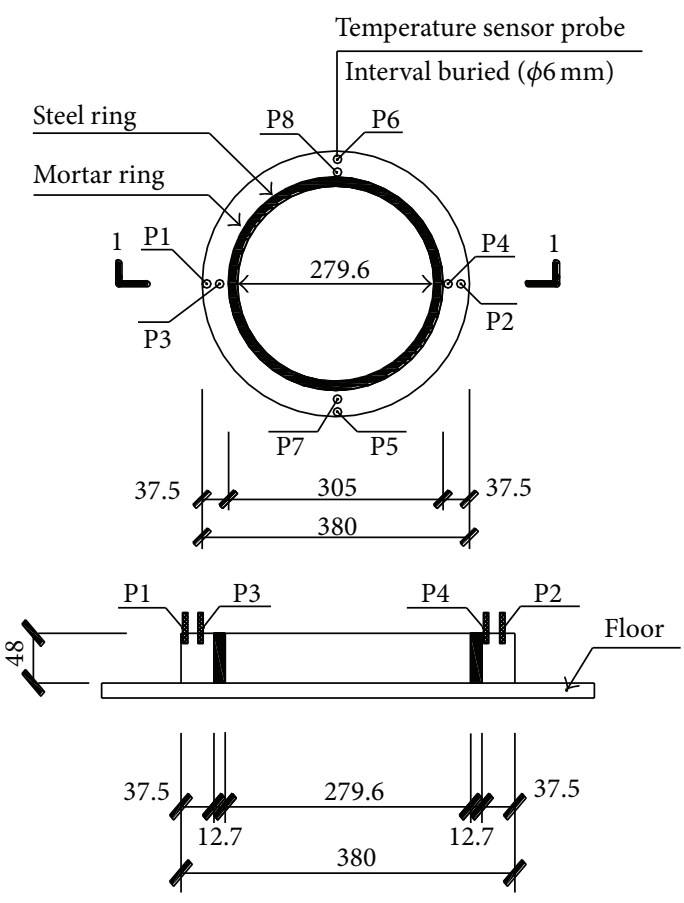

FIGURE 1: Restrained mortar ring and instruments.

as well [10-12]. The age of cracking of the mortar ring is predicted by comparing the maximum stress of the restrained ring with the split tensile strength.

\section{Constraint Ring Test}

2.1. Testing Method. The constraint ring test is the most commonly used method to evaluate the cracking of hardened material. Based on the standard for the ring test developed by AASHTO [13] being standardized recently by ASTM [14], three mortar ring specimens were casted. The inner diameter of the mortar ring was $305 \mathrm{~mm}$, the thickness was $37.5 \mathrm{~mm}$, and the height was $48 \mathrm{~mm}$. The restraining steel ring with the same height of the mortar had an inner diameter of $279.66 \mathrm{~mm}$, a thickness of $12.7 \mathrm{~mm}$. This geometry produces a degree of restraint of $60 \%$.

Four groups of temperature gauges were placed at $90^{\circ}$ from one another in the mortar ring to measure the temperature changes. The schematic of the mortar ring and the setting of the instruments is shown in Figure 1. The ingredients of the specimen were Portland cement (Lafarge PO42.5R) of $586 \mathrm{~kg} / \mathrm{m}^{3}$, medium sand (with grain size between $0.35 \mathrm{~mm}$ and $0.5 \mathrm{~mm}$ ) of $1758 \mathrm{~kg} / \mathrm{m}^{3}$, polycarboxylatic water-reducer of $5.86 \mathrm{~kg} / \mathrm{m}^{3}$, and water of $188 \mathrm{~kg} / \mathrm{m}^{3}$. The specimen was designed at a fixed water-to-cement ratio by weight of 0.32 and cement-to-sand ratio by weight of 0.33 .

The specimens were cast with mortars at $25 \pm 3^{\circ} \mathrm{C}$ and over $50 \%$ relative humidity (RH). After $24 \mathrm{~h}$, the specimens were demolded and placed in the drying chamber at $20 \pm$ $3^{\circ} \mathrm{C}$ and $50 \pm 4 \% \mathrm{RH}$. The change of the temperature was recorded and the age and width of cracking of the specimen were observed.

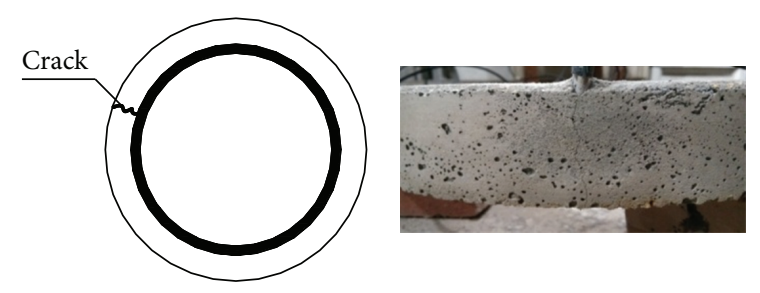

FIGURE 2: Cracking of the restraint ring.

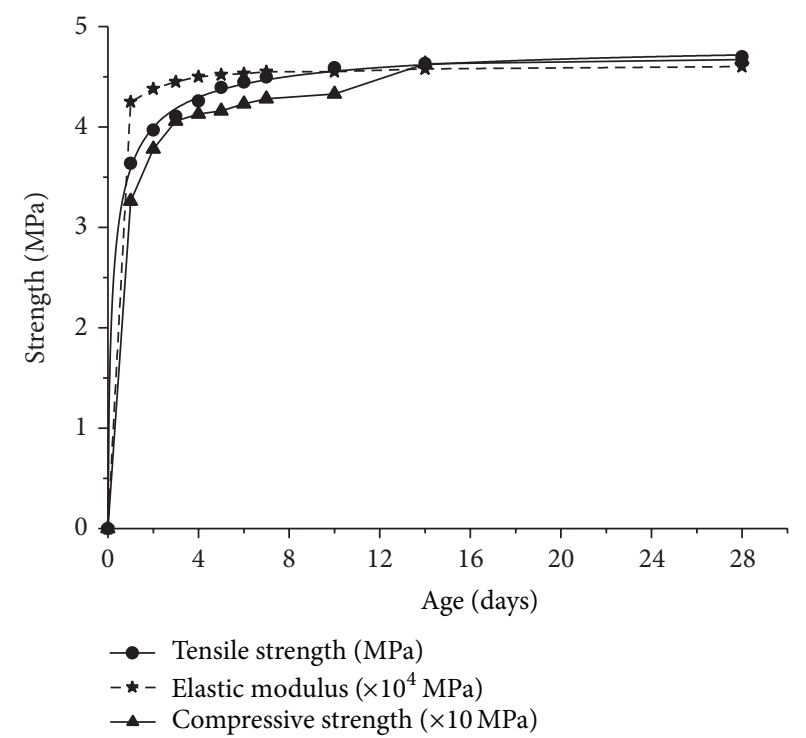

FIGURE 3: Compressive and splitting tensile strengths and elastic modulus of mortar.

Mortar prisms $\left(100 \times 100 \times 300 \mathrm{~mm}^{3}\right)$ were cast to measure elastic modulus and compressive strength, mortar prisms $\left(40 \times 40 \times 160 \mathrm{~mm}^{3}\right)$ to the split tensile strength, and the mortar prisms $\left(25 \times 25 \times 280 \mathrm{~mm}^{3}\right)$ to the free shrinkage, at 1 day (d), $3 \mathrm{~d}, 5 \mathrm{~d}, 7 \mathrm{~d}, 10 \mathrm{~d}, 14 \mathrm{~d}$, and $28 \mathrm{~d}$ successively. These specimens have the same mixture and were demolded at the same time and cured under the same conditions with the mortar rings. Mortar prisms $\left(100 \times 100 \times 400 \mathrm{~mm}^{3}\right)$ with the same mixture, demolding procedure, and cure condition were cast to measure creep. The displacement of the prism with loading was measured at $1 \mathrm{~d}, 3 \mathrm{~d}, 5 \mathrm{~d}, 7 \mathrm{~d}, 14 \mathrm{~d}$, and $28 \mathrm{~d}$ successively.

2.2. Testing Results and Analysis. The first crack was observed at the noon of $25 \mathrm{~d}$ after demolding of the restraint mortar ring. Then the cracking developed slowly. The cracking location and the phenomena are shown in Figure 2.

The mean values of the compressive strength, splitting tensile strength, and elastic modulus of mortar are shown in Figure 3 with respect to mortar age. According to Figure 3, the mechanical properties of the mortar developed rapidly in the first two days, and the development slowed down gradually. The elastic modulus reached its peak value at the 3 days. The curves of the strengths became steady after 7 days, and all 


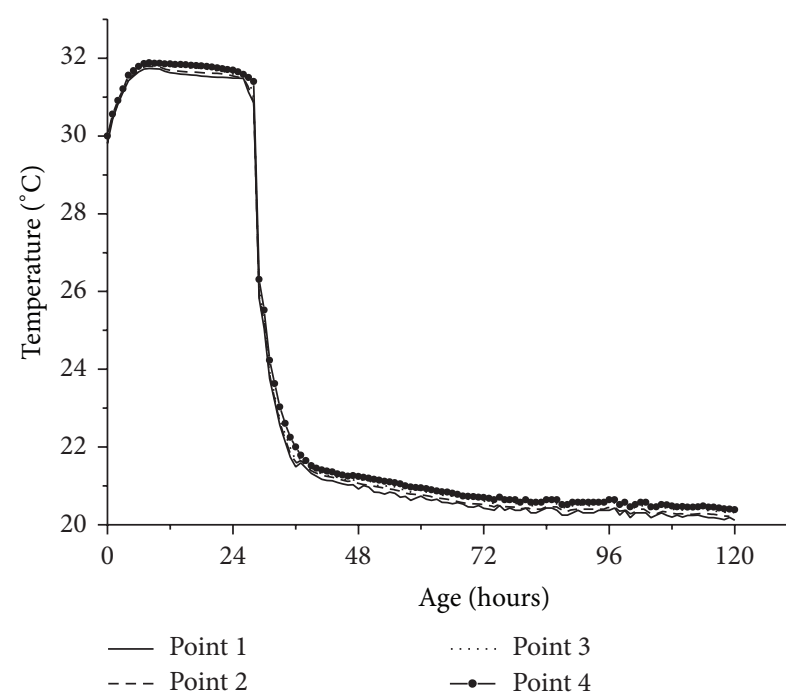

FIgURE 4: Measured temperature development of mortar ring.

the fluctuation of the mechanical properties of the mortar tended to be stable at 28 days.

Figure 4 shows the temperature developments of the mortar rings with age. The temperature increased due to the thermal effects in the beginning of hydration and reached the peak value, $31.7^{\circ} \mathrm{C}$, around 8 hours after demolding. The mortar rings cooled down very little in the next 18 hours. Then the temperatures of the mortar rings decreased steadily after they were moved to the drying chamber where the temperature was kept at $20^{\circ} \mathrm{C}$. This phenomenon coincides with the fact that the specific heat and thermal diffusivity decrease with the development of hydration. According to the temperature curves in Figure 4, which were measured at different location along the radius of the mortar ring, it can also be noticed that the temperature was getting lower from the inner surface to the outer. The temperature gradient of the mortar was not remarkable probably owing to the small thickness of the mortar ring.

In addition to the thermal shrinkage, shrinkages result from the consumption of water during the hydration processes and the chemical reaction between cement and water which is termed autogenous shrinkage and from the drying of the material which is termed drying shrinkage. In concrete, the shrinkage results in tensile stresses in the cement paste due to restraint from the aggregates and/or the refinement. The practical importance of shrinkage of the restrained cement paste has been recognized in recent years. Although the mechanism of autogenous shrinkage is not understood well, there is a general agreement about the driving factors which are the chemical shrinkage, the $\mathrm{RH}$ changes in the pores of the hardening cement, the changes in the surface tension of the solid gel particles, and disjoining pressure and tension in capillary water [15]. In high-performance concrete, the low $\mathrm{w} / \mathrm{c}$ ratio causes a significant drop in the internal $\mathrm{RH}$ in the cement paste [16], and the autogenous shrinkage plays an important part in the whole shrinkage, especially in the 1-2 days after the casting [17].
As mentioned before, the low w/c cementitious mixture may experience greater autogenous shrinkage, as well as drying and thermal contraction in the early-age. Restraint of this volumetric change by steel ring generates stress inside the mortar ring that may induce cracking. In real situation, the volumetric change and the residual stresses of the restrained ring are the results of the coupled interaction of all the aforementioned effects. For the purpose of simplification, it is sound to assume that the autogenous shrinkage, the drying process, and the thermal contraction are independent.

Weiss et al., by using acoustic emission, have shown that in rings that dry uniformly along the radius the cracking begins at the inner circumference of the rings while in specimens that dry from the outer circumference of the rings the cracks begin at the outer edge and propagate toward the center [18-20]. They have proposed that the drying direction (see from top, bottom, or lateral side of the specimen and so on) as well as the moisture gradient is important for the simulation of residual stresses. Although the importance of moisture gradients in shrinkage and cracking was pointed forward early [21], little has been revealed for the true moisture field due to the combination effects of thermal hydration and circumstance drying process.

By using the rotronic hygroscope, Sant [22] has proposed that the internal equilibrium $\mathrm{RH}$ is a function of cured temperature measured on mature cement pastes. The internal $\mathrm{RH}$ is observed to decrease (or increase) linearly with decreasing (or increasing) temperature. The residual stresses development of early-age mixtures due to autogenous shrinkage is expected to be slightly higher, as a lower equilibrium $\mathrm{RH}$ in the early-age mixtures specimens, while the rate of residual stress development increases with increasing cured temperature. Moon and Weiss have shown that, at initial drying times, the stress development in a concrete ring is mainly governed by self-restraint due to the inner $\mathrm{RH}$, while it is mainly governed by the external steel ring restraint for longer drying periods [20]. Based on the drying situation of the present test in this paper, which is dried from the top, bottom, and lateral sides of the restrained ring, it is reasonable and practical to assume that the moisture of the mortar ring is uniform in the ongoing simulation of the residual stresses.

The measured shrinkage strains with respect to age are shown in Figure 5 in dot. It can be seen that, in the first 2 days, the shrinkage strains grew dramatically, and in the following 5 days, the shrinkage kept on increasing slowly. After 7 days, with the development of hydration and hardening of the cement paste, the shrinkage deformation tended to be plateau. Based on the research works by Yang et al. [16], for the high-performance cementitious materials of low $\mathrm{w} / \mathrm{c}$ ratio in the present test, the autogenous shrinkage is dominant to the volumetric variations of the specimen in the first 2 days. By using the prediction model of autogenous shrinkage for prism specimen with w/c ratio of 0.32 proposed by Wang and $\mathrm{Li}$ [23], the simulation of autogenous shrinkage strain $\varepsilon_{\mathrm{AS}}$ for the mortar ring in the present test, with the autogenous shrinkage strain being $200 \times 10^{-6}$ at $28 \mathrm{~d}$, can be expressed as

$$
\varepsilon_{\mathrm{AS}}=237 \frac{t^{0.3}}{t^{0.3}+0.5} \times 10^{-6} .
$$




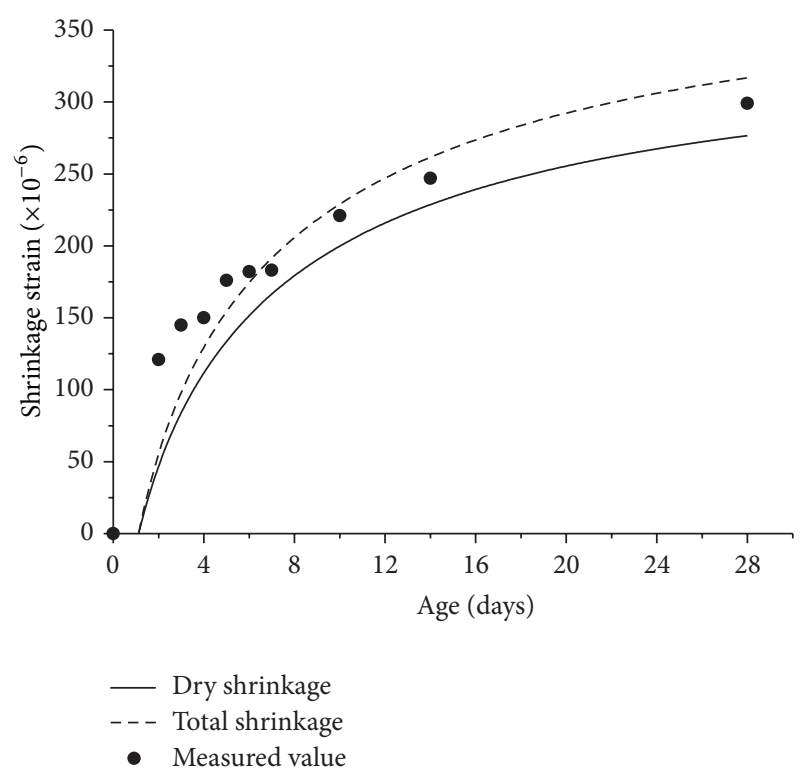

FIGURE 5: Measured shrinkage strains and analyzing results.

For simplification, the geometry effects of specimen are ignored and the autogenous shrinkage strain in (1) is regarded as those of restrained ring. According to Figure 5, it can be seen that the drying shrinkage plays an important role in the shrinkage of mortar after 2 days. To be assumed as uniform drying, and by using CEB/FIP MC90 drying shrinkage model [24], the drying shrinkage $\varepsilon_{\mathrm{DS}}\left(t, t_{\mathrm{DS}}\right)$ is simulated as follows:

$$
\varepsilon_{\mathrm{DS}}\left(t, t_{\mathrm{DS}}\right)=\varepsilon_{\mathrm{DS}}\left(f_{c 28}\right) \beta_{\mathrm{RH}} \beta_{\mathrm{DS}}\left(t, t_{\mathrm{DS}}\right),
$$

where $\varepsilon_{\mathrm{DS}}\left(f_{c 28}\right)$ is the drying shrinkage strain of mortar at $28 \mathrm{~d}, t_{\mathrm{DS}}$ is the initial time for drying, here at $1 \mathrm{~d}$, and $\beta_{\mathrm{RH}}$ and $\beta_{\mathrm{DS}}\left(t, t_{\mathrm{DS}}\right)$ are the coefficients of the circumstance $\mathrm{RH}(50 \%$ in the present test) and geometry effect which are shown as follows, respectively:

$$
\begin{aligned}
& \beta_{\mathrm{RH}}=1.55\left(1-\left(\frac{\mathrm{RH}}{100}\right)^{3}\right)=1.36 \\
& \beta_{\mathrm{DS}}\left(t, t_{\mathrm{DS}}\right)=\sqrt{\frac{\left(t-t_{\mathrm{DS}}\right)}{0.035 h^{2}+\left(t-t_{\mathrm{DS}}\right)}}=\sqrt{\frac{t-1}{t+8.8}} .
\end{aligned}
$$

Based on (2), the drying shrinkage strain of prisms in the present test is simulated as in

$$
\varepsilon_{\mathrm{DS}}(t)=512\left(\frac{t}{t+9.8}\right)^{0.5} \times 10^{-6} .
$$

The total shrinkage of testing prism is the sum of the autogenous shrinkage $\varepsilon_{\mathrm{AS}}$ and drying shrinkage $\varepsilon_{\mathrm{DS}}$. Figure 5 showed the simulating results of total shrinkage in solid line. The simulation result agrees well with the measured data that enable the continuous analysis of the shrinkage stress to be practical and rational. It is quite interesting that the shrinkage ignoring the autogenous shrinkage results in much lower estimation in the first few days. This implies

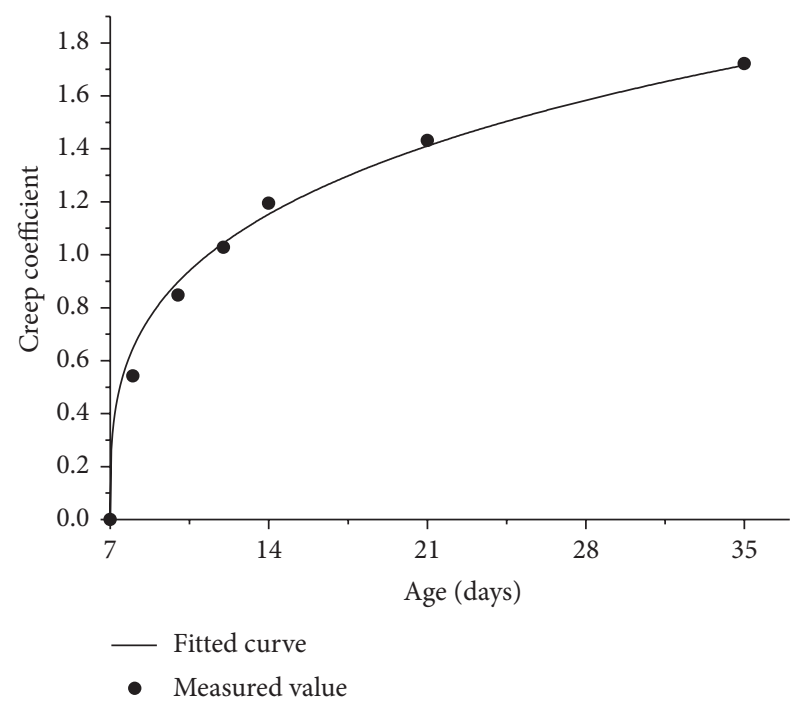

FIGURE 6: Measured creep coefficients and analyzing result.

that the autogenous shrinkage has important role in highperformance concrete of low w/c ratio in the very early-age of mortar.

Considering the geometry effects of the drying shrinkage, CEB/FIP model [24] which is based on the specimen of prism is adjusted for the case of present mortar ring. The total shrinkage analytical model of mortar ring which is the combination of autogenous shrinkage and drying shrinkage is given in

$$
\begin{aligned}
\varepsilon_{S}(t) & =\varepsilon_{\mathrm{AS}}(t)+\varepsilon_{\mathrm{DS}}(t) \\
& =\left[512\left(\frac{t}{t+61.7}\right)^{0.5}+237 \frac{t^{0.3}}{t^{0.3}+0.5}\right] \times 10^{-6} .
\end{aligned}
$$

During the development of residual stress, creep has an important role in the relaxation to the stress. The short term creep strains in the early-age are the slow, progressive deformation of materials under constant stress. The creep strains are sensible to temperature changes, leading to transient thermal creep, and to moisture exchanges with the environment, resulting in a phenomenon of drying creep. The creep contributes up to $40 \%-50 \%$ reduction of the elastically induced residual stress in the restrained specimen $[25,26]$. Several models have been presented, such as ACI209 [27], B3 model by Bazant and Murphy [28], and CEB-FIP [24] model. Almost all the present models are empirical models which are regressed and fit based on the statistics of particular experimental data. By now, none of these models could provide a well-received prediction of the creep trend for all experimental or practical situations.

In Figure 6, based on the creep test of mortar prisms, the creep coefficient, which is the ratio of the creep deformation to the elastic deformation under constant compressive load, with respect to age, is shown. It is noticed that the development of the creep deformation was faster in the first few days and slowed down with hardening process. 
CEB/FIP model [24] is a commonly used practical model to deal with the prediction of the creep deformation for the early-age cementitious materials. It is based on large amount of experimental data and is verified by some practical projects. As mentioned before, the short term creep of the early-age cementitious materials depends on the change of humidity, temperature, strength, and elastic modulus of the cement paste and on the thickness of the cement ring, and so on. Taking into account the factors of $\mathrm{RH}$, the geometry effect of specimen, the compressive strength of materials, and the loading time, the simulation of creep coefficient according to $\mathrm{CEB} / \mathrm{FIP}$ is as follows:

$$
\varphi_{\mathrm{CR}}\left(t, t_{0}\right)=\varphi_{\mathrm{RH}} \cdot \beta\left(f_{\mathrm{cm}}\right) \cdot \beta\left(t_{0}\right) \cdot \beta_{c}\left(t-t_{0}\right),
$$

where $\varphi_{\mathrm{RH}}$ is the coefficient related to $\mathrm{RH}$ and nominal dimensions $h$, depending on specimens size and shape,

$$
\varphi_{\mathrm{RH}}=1+\frac{[1-(\mathrm{RH} / 100)]}{\left[0.46(h / 100)^{1 / 3}\right]} .
$$

$\beta\left(f_{\mathrm{cm}}\right)$ and $\beta\left(t_{0}\right)$ are the coefficients related to compressive strength of specimens and loading age, respectively, $\beta\left(f_{\mathrm{cm}}\right)=$ $5.3 / \sqrt{f_{\mathrm{cm}} / 10}$ and $\beta\left(t_{0}\right)=1 /\left[0.1+\left(t_{0}\right)^{0.2}\right], \beta_{c}\left(t-t_{0}\right)$ is the timedependent coefficient related to both the $\mathrm{RH}$ and nominal dimensions of specimen, $\beta_{c}\left(t-t_{0}\right)=\left[\left(t-t_{0}\right) /\left(\beta_{H}+\left(t-t_{0}\right)\right)\right]^{0.3}$ while $\beta_{H}=1.5 h \cdot\left[1+(0.012 \mathrm{RH})^{18}\right]+250$, and $t_{0}$ is the initial time of the creep.

Based on (6), the simulated expression of creep coefficient for the present casting prisms, $\varphi_{\mathrm{CR}}^{P}(t, 7)$, is obtained:

$$
\varphi_{\mathrm{CR}}^{P}(t, 7)=3.67\left[\frac{t-7}{(t-7)+325}\right]^{0.3}
$$

in which, according to loading history, the initial time of the creep, $t_{0}$, is at $7 \mathrm{~d}$. The analysis results of the creep coefficient with respect to age are shown in Figure 6 in solid line. Compared to the creep coefficient based on the testing data, the prediction model provides satisfactory simulation results. Therefore, considering the effects of the geometry effects of the mortar ring, the creep coefficient with age, $\varphi_{\mathrm{CR}}\left(t, t_{0}\right)$, is predicted as in the following:

$$
\varphi_{\mathrm{CR}}\left(t, t_{0}\right)=6.0\left(\frac{1}{0.1+t_{0}^{0.2}}\right)\left[\frac{t-t_{0}}{\left(t-t_{0}\right)+313}\right]^{0.3} .
$$

\section{Thermal Stress Analysis due to Hydration}

3.1. Temperature Development due to Hydration. As mentioned before, the effects of autogenous shrinkage, drying process, and thermal contraction are assumed to be developed independently with each other. Therefore, the stress developments due to shrinkage and thermal contraction could be analyzed separately and independently.

The thermal characteristics of early-age mortar ring have an important role in cracking. It is concluded that the specific heat and thermal diffusivity decrease with the degree of hydration. With the hydration model and the evolving thermal characteristics, the temperature field in a cementitious material element can be calculated accurately by solving the nonstationary Fourier boundary value problem. This is verified experimentally by means of massive hardening concrete cylinders. The equation of heat conduction of the mortar ring in polar coordination form can be written in the following:

$$
\frac{\partial T(t, r)}{\partial t}-a \frac{\partial^{2} T(t, r)}{\partial r^{2}}-\frac{a}{r} \frac{\partial T(t, r)}{\partial r}=\frac{Q_{m}}{c \rho},
$$

where $a$ is the thermal diffusion coefficient of cement, $a=$ $k / c \rho ; k, c$, and $\rho$ are the coefficients of thermal conductivity, specific heat, and density of mortar, respectively; $Q_{m}$ is the rate of hydration heat, $Q_{m}=\mathrm{d} Q / \mathrm{d} t$, while $Q$ is the hydrate heat of mortar. There are several models to imitate the hydrate heat of cementitious materials in early-age. The exponential function of hardening age shown as in the following [27] is commonly used:

$$
Q=Q_{0}\left(1-e^{-m t}\right)
$$

where $Q_{0}$ is the hydrate heat per kilogram cement, taken as $340 \mathrm{~kJ} / \mathrm{kg}$ in this test, and $m$ is the coefficient of hydrate rate, taken as $0.312 ; t$ is the age of the cement paste. The initial condition is $T(0, r)=T_{c}, T_{c}$ being the circumstantial temperature. Because of the small thickness of the steel ring, the heat conduction difference between the mortar ring and the steel ring could be ignored, neither the deformation of the steel ring due to the temperature. The ignorance indicates that the inner and outer surface of the mortar ring could be both regarded as the third thermal boundary condition as follows:

$$
-k \frac{\partial T(t, r)}{\partial r}=h\left(T-T_{C}\right)
$$

where $T$ is the temperature of the mortar surface and $T_{c}$ the circumstantial temperature. $h$ is the convective heat transfer coefficient between the cement ring and the air, being taken for $4.74 \mathrm{~W} /\left(\mathrm{m}^{2} \mathrm{~K}\right)$ here.

The hydration process described by (10)-(12) can be solved by difference method which is shown as follows:

$$
\begin{aligned}
T_{i}^{j}= & \left(1-\frac{2 a \Delta t}{\Delta r^{2}}\right) T_{i}^{j-1} \\
& +\frac{a \Delta t}{\Delta r^{2}}\left[\left(T_{i+1}^{j-1}+T_{i-1}^{j-1}\right)+\frac{\Delta r}{2 r}\left(T_{i+1}^{j-1}-T_{i-1}^{j-1}\right)\right] \\
& +\frac{Q_{m} \Delta t}{c \rho},
\end{aligned}
$$

where the super- and subscript of $T$ are the time and location point, respectively, and $\Delta r$ is the increment between the points in the radius.

The difference type of the boundary condition is

$$
k \frac{T_{2}^{j}-T_{0}^{j}}{2 \Delta r}=h\left(T_{1}^{j}-T_{c}\right)
$$




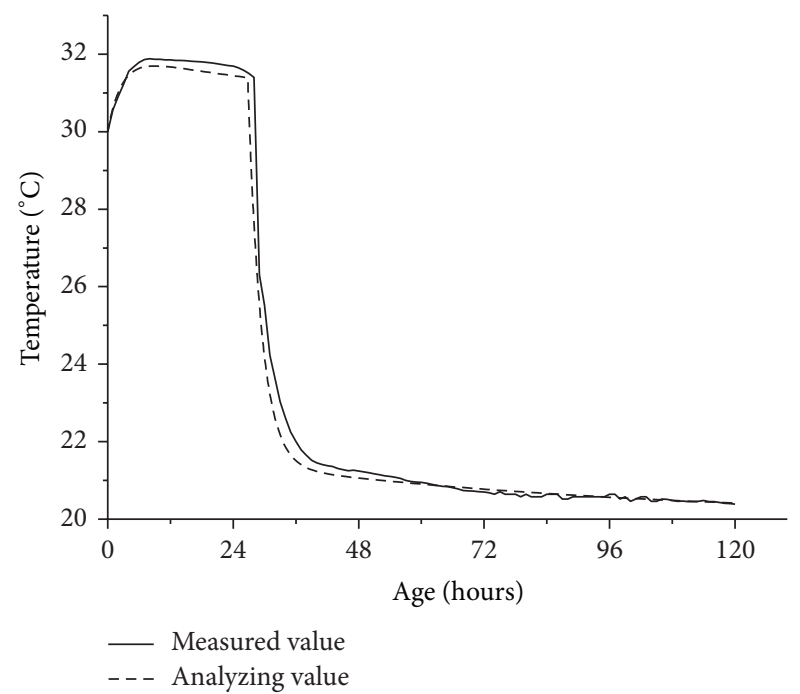

Figure 7: Predicting temperature development at Point 4.

Introducing (14) into (13) and eliminating $T_{0}^{j}$, one can get

$$
\begin{aligned}
T_{1}^{j}= & \left(1-\frac{2 a \Delta t}{\Delta r^{2}}-\frac{2 a h \Delta t}{k \Delta r}+\frac{a h \Delta t}{k r}\right) T_{1}^{j-1} \\
& +\frac{2 a \Delta r}{\Delta r^{2}} T_{2}^{j-1}+\left(\frac{2 a h \Delta t}{k \Delta r}-\frac{a h \Delta t}{k r}\right) T_{c}+\frac{Q_{m} \Delta t}{c \rho} \\
T_{m}^{j}= & \left(1-\frac{2 a \Delta t}{\Delta r^{2}}-\frac{2 a h \Delta t}{k \Delta r}-\frac{a h \Delta t}{k r}\right) T_{m}^{j-1} \\
& +\frac{2 a \Delta r}{\Delta r^{2}} T_{m-1}^{j-1}+\left(\frac{2 a h \Delta t}{k \Delta r}+\frac{a h \Delta t}{k r}\right) T_{c}+\frac{Q_{m} \Delta t}{c \rho},
\end{aligned}
$$

where $T_{1}^{j}$ and $T_{m}^{j}$ are the temperatures at the inner and outer surface of the mortar ring correspondingly. The analysis results of temperature development due to hydrate heat at Point 4 of the mortar ring are shown in Figure 7 in dashed line. It is noted that the simulating result coincides with the measured data, which is plotted in solid line, quite well.

3.2. Thermal Stresses Analysis. The thermal residual stresses developed in the mortar ring are thought to be a combination of the self-restraint stresses due to the temperature gradient of the ring and the restraint stresses provided by the steel ring. Based on this, an analytical equation based on elasticity theory is applied to compute the residual thermal stress field that develops in the restrained ring. The materials are assumed to be elastic, continuous, and uniform, and the thermal deformation is uniform along the circumference. First of all, let us assume that the steel would not deform subjected to the compression stresses due to the shrinkage of the mortar ring because of the relative strong stiffness of the steel ring to the mortar ring in early-age. The equilibrium equation of the circumferential thermal stress $\sigma_{\theta}^{T}$ and the radius thermal stress $\sigma_{r}^{T}$ at radius $r$ for the axisymmetric problem is

$$
\frac{\partial \sigma_{r}^{T}}{\partial r}+\frac{\sigma_{r}^{T}-\sigma_{\theta}^{T}}{r}=0
$$

with the compatible condition,

$$
\varepsilon_{r}^{T}=\frac{d u_{r}^{T}}{d r} \varepsilon_{\theta}^{T}=\frac{u_{r}^{T}}{r}
$$

and the constitutive condition for elastic deformation,

$$
\begin{aligned}
\varepsilon_{r}^{T} & =\frac{1}{E(t)}\left(\sigma_{r}^{T}-\mu \sigma_{\theta}^{T}\right)+\alpha^{T} T, \\
\varepsilon_{\theta}^{T} & =\frac{1}{E(t)}\left(\sigma_{\theta}^{T}-\mu \sigma_{\theta}^{T}\right)+\alpha^{T} T,
\end{aligned}
$$

where $E, \mu, \alpha^{T}$ are the elastic modulus, Poisson ratio, and thermal expansion coefficient of cement, respectively, $\alpha^{T}=$ $1 \times 10^{-5} /{ }^{\circ} \mathrm{C}$. The Poisson ratio is nonvariable during the hydration of mortar. The elastic modulus $E$, stresses and strains in the direction of radius and circumference are all time-variant. The boundary conditions are $u_{r}^{T}=0$ at $r=R_{1}$; $\sigma_{r}^{T}=0$ at $r=R_{2}$, where $R_{1}$ and $R_{2}$ are the inner and outer radius of the mortar ring, respectively.

Substituting (17) and (18) into equilibrium equation (16) results in

$$
\frac{d}{d r}\left[\frac{1}{r} \frac{d}{d r}\left(r u_{r}^{T}\right)\right]=(1+\mu) \alpha^{T} \frac{d T}{d r} .
$$

By integrating (19), the radial components of the deformation due to hydration heat are obtained as

$$
u_{r}^{T}=\frac{(1+\mu) \alpha^{T}}{r} \int_{R_{1}}^{r} T(r, t) r d r+C r+\frac{D}{r},
$$

where $C$ and $D$ are the integrating constants determined by boundary conditions.

The stress components, that is, stress in radial direction $\sigma_{r}^{T}$ and stress in circumferential direction $\sigma_{\theta}^{T}$, can be expressed in radial components of the deformation as in the following:

$$
\begin{aligned}
\sigma_{r}^{T}= & -\frac{E(t) \alpha^{T}}{r^{2}} \int_{R_{1}}^{r} T(r, t) r d r \\
& +\frac{E(t)}{1-\mu^{2}}\left[(1+\mu) C-(1-\mu) \frac{D}{r^{2}}\right], \\
\sigma_{\theta}^{T}= & \frac{E(t) \alpha^{T}}{r^{2}} \int_{R_{1}}^{r} T(r, t) r d r \\
& +\frac{E(t)}{1-\mu^{2}}\left[(1+\mu) C-(1-\mu) \frac{D}{r^{2}}\right]-E(t) \alpha^{T} T .
\end{aligned}
$$

Substituting the simulating results of temperature development with age obtained by using (15) or the testing data shown in Figure 7, (21) can be solved by incremental method. The analytical results of the time-dependent thermal residual stresses are shown in Figure 8. 


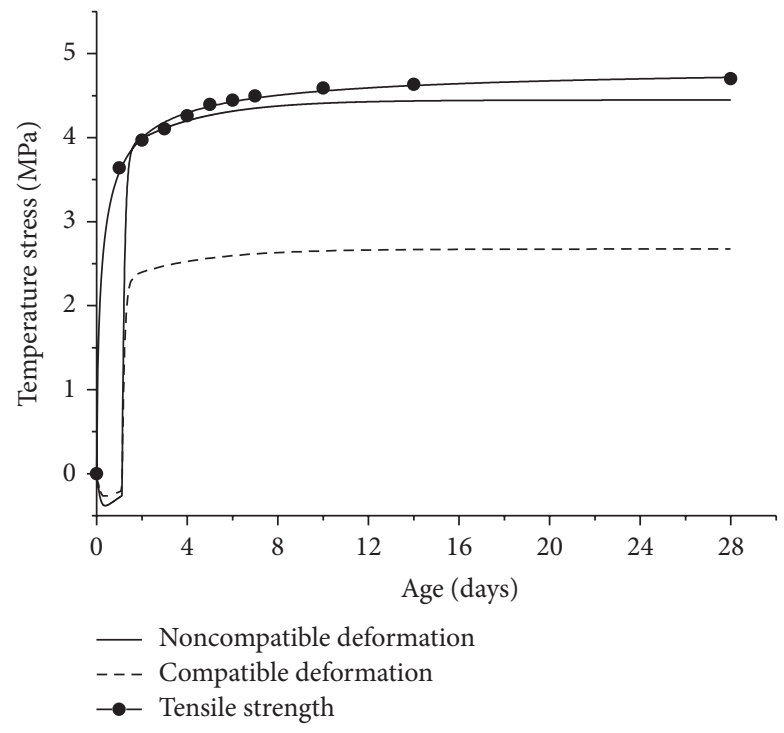

(a)

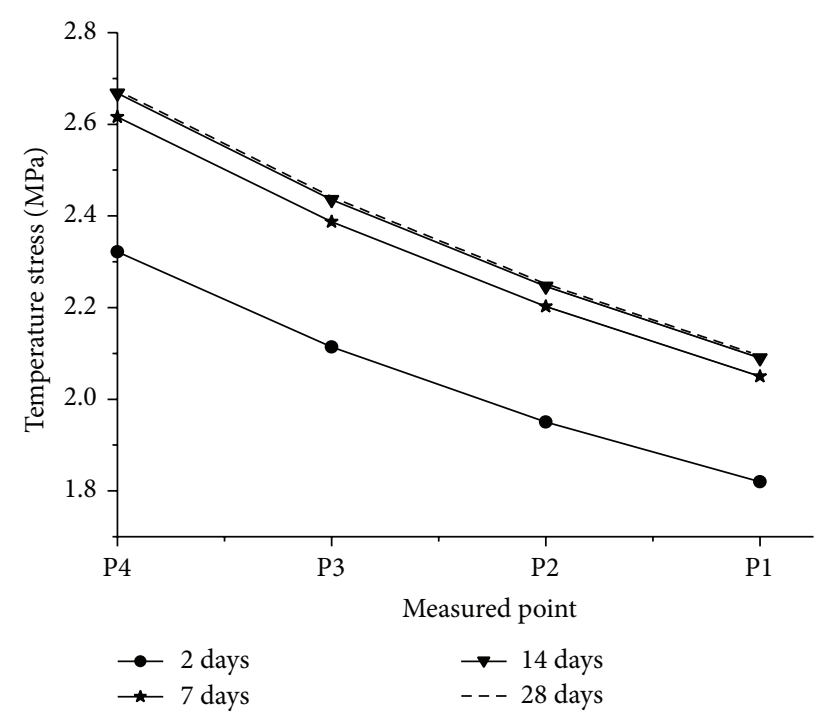

(b)

Figure 8: Thermal residual stress development with age. (a) Thermal residual stress at Point 4; (b) thermal residual stress distribution with age.

According to the solid line in Figure 8(a), which illustrated the development of the stress at Point 4 in the inner surface of mortar ring, the thermal stress was negative in the first 2 days; then, it increased to be positive steeply at $3 \mathrm{~d}$ and turned to be steady with time. The negative, or compressive, stress is caused by the constraint of mortar expansion in heating process of hydrate. With the development of hydration, the mortar ring began to shrink caused by the drop of the temperature. The shrinkage in the inner surface of the mortar ring was constrained by the steel ring to result in tensile stress in the mortar ring. The residual thermal stress decreased from the inner-to-outer surface in a linear way, according to Figure 8(b). The linear distribution of the thermal stress in the mortar ring is due to the uniform hydrate process of the thin specimen. The maximum stress developed in the circumferential direction along the interface between concrete and steel because of the relative strong restraint of the steel by ignoring either the thermal or the compressive deformation.

Compared to the tensile strength of mortar in dotted line in Figure 8(a), the thermal residual stress almost reached the strength at $3 \mathrm{~d}$ and then kept lower to the strength with age. This indicates the cracking risk in the very early-age of the restrained mortar ring.

\section{Shrinkage Stresses Analysis}

Notice that equations of strains and stresses for restraint hydrate process of the ring are also able to be used in the case of uniform radial shrinkage by reforming the constitutive equation for uniform shrinkage:

$$
\frac{\partial \sigma_{r}^{\mathrm{SH}}}{\partial r}+\frac{\sigma_{r}^{\mathrm{SH}}-\sigma_{\theta}^{\mathrm{SH}}}{r}=0 .
$$

The compatible equations for shrinkage are

$$
\begin{aligned}
& \varepsilon_{r}^{\mathrm{SH}}=\frac{d u_{r}^{\mathrm{SH}}}{d r}, \\
& \varepsilon_{\theta}^{\mathrm{SH}}=\frac{u_{r}^{\mathrm{SH}}}{r}
\end{aligned}
$$

and the relationship between the shrinkage strain and the restrained stresses is

$$
\begin{aligned}
& \varepsilon_{r}^{\mathrm{SH}}=\frac{1}{E(t)}\left(\sigma_{r}^{\mathrm{SH}}-\mu \sigma_{\theta}^{\mathrm{SH}}\right)+\varepsilon^{\mathrm{SH}}, \\
& \varepsilon_{\theta}^{\mathrm{SH}}=\frac{1}{E(t)}\left(\sigma_{\theta}^{\mathrm{SH}}-\mu \sigma_{r}^{\mathrm{SH}}\right)+\varepsilon^{\mathrm{SH}},
\end{aligned}
$$

where $\varepsilon^{\mathrm{SH}}$ is the composite shrinkage of autogenous and drying of the mortar ring. As mentioned before, $\varepsilon^{\mathrm{SH}}$ is dependent on $\mathrm{RH}$, temperature, and the pore structure of the cementitious materials. To be simple, and also rational, $\varepsilon^{\mathrm{SH}}$ could be assumed as a linear function of $\mathrm{RH}$ with the shrinkage strain coefficient, $\alpha^{\mathrm{SH}}$. In this paper, $\varepsilon^{\mathrm{SH}}$ is obtained according to either the testing results shown in Figure 5 or the analysis prediction function in (5). The elastic modulus, Poisson ratio, and the boundary conditions are much the same as those in the thermal stresses phenomena.

The shrinkage stresses $\left(\sigma_{r}^{\mathrm{SH}}, \sigma_{\theta}^{\mathrm{SH}}\right)$ can also be solved by incremental method. The analytical results of the timedependent residual stress due to shrinkage are shown in Figure 9. The increasing tendency of shrinkage stresses, tensile stresses, varied rapidly in the first 7 days and slowed down after that. According to Figure 9(b), the circumferential maximum tensile stress due to shrinkage is at the inner surface of the mortar ring, the same distribution as that of the thermal stresses in Figure 8(b). 


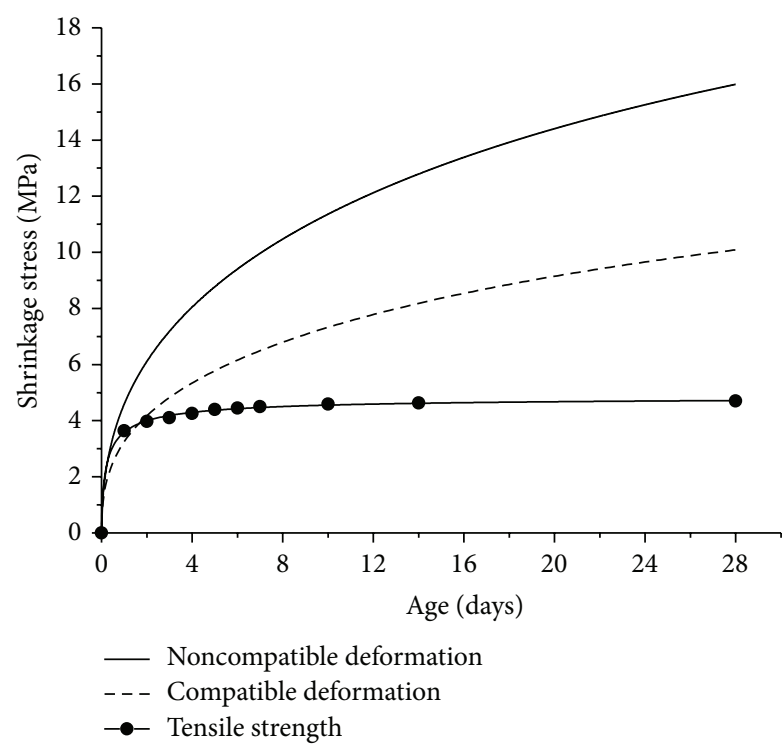

(a)

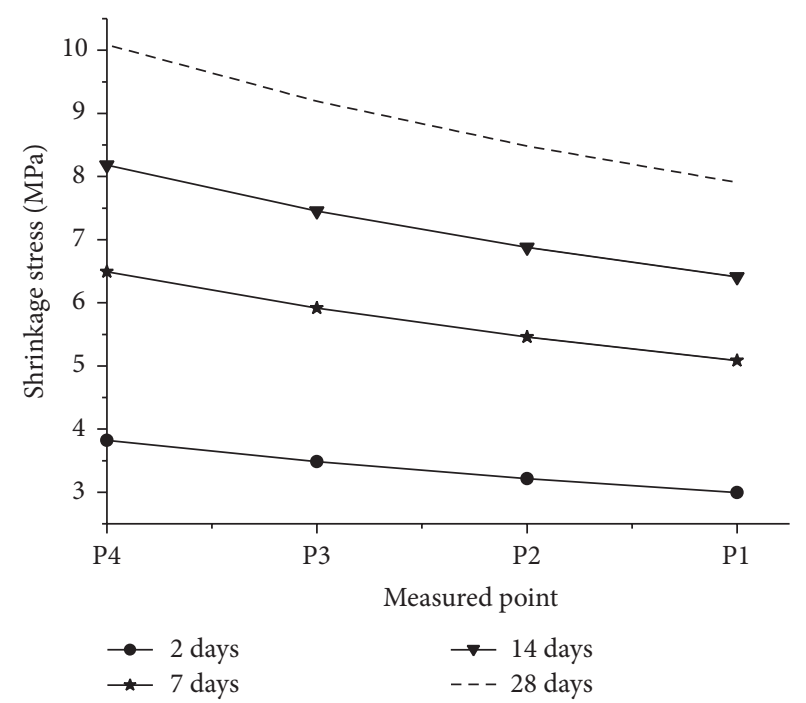

(b)

FIGURE 9: Shrinkage residual stress development with age of mortar. (a) Shrinkage residual stresses at Point 4; (b) shrinkage residual stress distribution.

It is noticeable that the shrinkage induced stress reached the tensile split strength of the specimen at the 1 day that indicates the early cracking of the mortar ring. This is untrue according to the cracking observation of the present test.

According to the simulation results shown in Figures 8(a) and 9(a), there are evident errors compared to the observation of the cracking of the restrained mortar ring. It is inferred that both of the simulation of the residual thermal stresses and shrinkage stresses are overestimated, which suggested the much earlier cracking tendency of the restrained mortar ring. Therefore, it is logical to introduce the relaxing effects to the restraint stresses of the mortar ring.

One of the reasons to induce the error of restraint stresses prediction is the overestimation of restraint effects of steel ring. In the above analysis process, the steel ring is regarded as solid support to the mortar ring. In fact, with the development of the hydration and the increase of the elastic modulus, the restraint of the steel ring to the mortar ring is reduced and the steel ring itself will shrink with the interaction between the steel ring and the mortar ring. This compatible deformation between steel ring and mortar ring will reduce the restraint residual tensile stress in the mortar ring. To account for the mismatch between the new radius of the mortar ring and the original outer radius of the steel ring, a shrink-fit approach, illustrated in Figure 10, is proposed by Weiss et al. [10]. A pressurizing force, $p$, can be thought to be applied to the interface between the steel ring and the mortar ring. This pressuring force acts to compress the steel ring and expand the mortar ring until displacement compatibility is achieved. The increment of the interface pressure between the steel and the mortar can be calculated as [10]

$$
\Delta p_{\mathrm{SH}}(t)=\frac{R_{S}(t) E(t) \Delta \varepsilon_{\mathrm{SH}}(t)}{\left(R_{2}^{2}+R_{1}^{2}\right) /\left(R_{2}^{2}-R_{1}^{2}\right)+v},
$$

where $R_{S}$ is the restraint degree of the steel ring which is calculated by

$$
R_{S}(t)=\frac{A_{s} E_{s}}{A_{s} E_{s}+A_{c} E(t)} .
$$

The circumferential tensile stress in the mortar ring along the radial direction is computed using the elastic stress solution for a pressurized cylinder shown in the following:

$$
\begin{aligned}
& \Delta \sigma_{\theta}(t)=\frac{R_{2}^{2} / r_{i}^{2}+1}{R_{2}^{2} / R_{1}^{2}-1} \Delta p(t), \\
& \Delta \sigma_{r}(t)=\frac{R_{2}^{2} / r^{2}-1}{R_{2}^{2} / R_{1}^{2}-1} \Delta p(t) .
\end{aligned}
$$

The same idea can be used for modifying the restraint thermal stresses. The modified circumferential maximum tensile stresses due to hydration and shrinkage are shown in Figures 8(a) and 9(a) in dashed line, respectively. Comparing with the stresses ignoring the deformation of the steel ring, the residual stresses considering the compatible deformation are much smaller.

\section{Strain Creep and Stress Relaxation Analysis}

Besides the elastic mechanical behaviour of early-age cementitious materials as presented formerly, also the viscoelastic mechanical behaviour, that is, the strain creep and stress relaxation, can affect the actual residual stress. The relationship between the strain and the stress considering the creep effect is proposed by Bazant and Murphy shown as [28]

$$
\varepsilon(t)=\frac{\sigma(t)}{E\left(t, t_{0}\right)}=\frac{\sigma(t)}{E\left(t_{0}\right)}\left[1+\varphi\left(t, t_{0}\right)\right], \quad t \geq t_{0},
$$




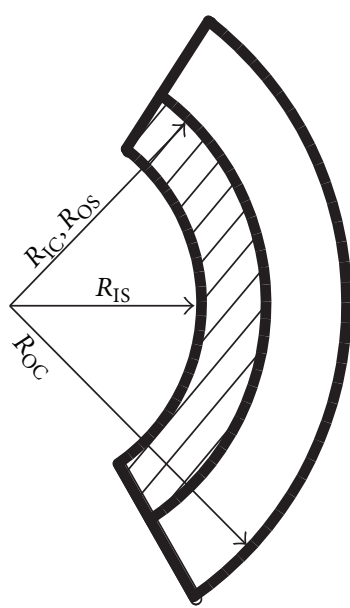

(a)

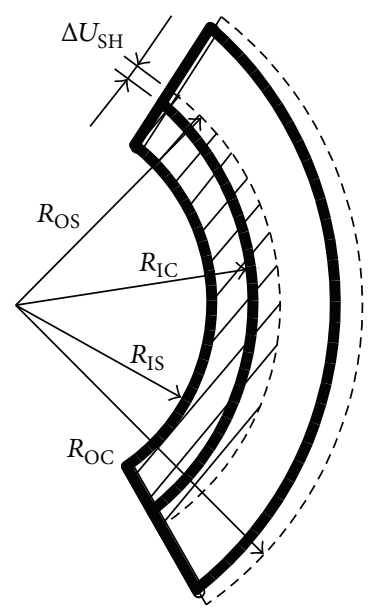

(b)

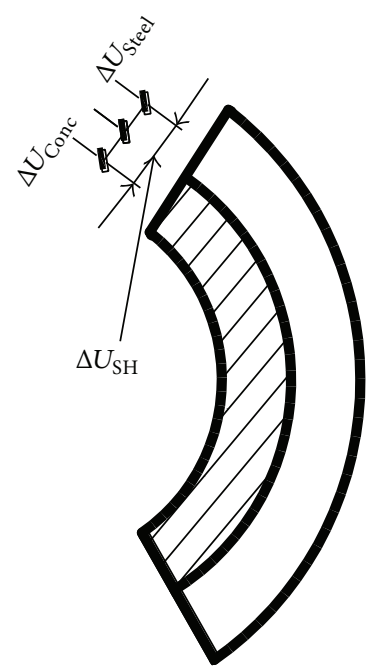

(c)

FIGURE 10: Illustration of the compatible deformation between the steel ring and the mortar ring. (a) Before mortar shrinkage; (b) removing constraint and allowing the mortar to shrink; (c) final geometry satisfying boundary condition [10].

where $E\left(t, t_{0}\right)$ is the effective modulus of mortar at time $t$ by taking into account creeping effect. In common sense, the modulus at 28 days tends to be constant. The stress relaxation coefficient $K$ can then be expressed in the following [28]:

$$
K\left(t, t_{0}\right)=\frac{\sigma(t)}{\sigma\left(t_{0}\right)}=\frac{E(28)}{E(28)+\varphi\left(t, t_{0}\right) E\left(t_{0}\right)}
$$

in which $t_{0}$ is the initial time of creep and $\varphi\left(t, t_{0}\right)$ is the creep coefficient of mortar given in (6) or (9) or by the testing data in Figure 6. According to the present creep test, $t_{0}$ is at 7 days.

The actual residual stress in the early-age of the restraint mortar ring is the comprehensive response of the thermal stress, the autogenous and drying shrinkage stress, and the relaxing effects due to the viscoelastic nature of the cementitious materials in early-age. This comprehensive response can be calculated in incremental method in

$$
\begin{aligned}
& \Delta \sigma_{\theta}\left(t_{i}\right)=K\left(t_{i}, t_{0}\right)\left(\Delta \sigma_{\theta}^{T}\left(t_{i}\right)+\Delta \sigma_{\theta}^{\mathrm{SH}}\left(t_{i}\right)\right), \\
& \Delta \sigma_{r}\left(t_{i}\right)=K\left(t_{i}, t_{0}\right)\left(\Delta \sigma_{r}^{T}\left(t_{i}\right)+\Delta \sigma_{r}^{\mathrm{SH}}\left(t_{i}\right)\right) .
\end{aligned}
$$

The actual residual stress at time $t$ is the sum of all the stress increments due to hydrate heat and shrinkage while considering the creeping effects.

The final comprehensive residual stresses of restrained mortar ring are shown in Figure 11. By comparing with the stress ignoring the effect of creep, the reduction in stress level due to creep is significant for early-age mortar, up to $60 \%$ of the elastically induced residual stress in the restrained specimen. The ignorance of the creep effect would introduce grand error in stress development estimation. Although further work is needed to compare the ring measurements with more standard creep or relaxation and to extend the data reduction to provide a more specific parameter such as specific creep or compliance, the present approach provides a practical method to quantify the comprehensive residual stresses of restrained mortar ring.

\section{The Cracking Tendency Prediction}

In practical application, the cracking potential estimation or, in other words, the measurement of how close the specimen may be to failure is more interesting for engineering practice. Comparing the residual stress level with the strength of materials provides a powerful tool to determine the cracking tendency in cases where cracking is not observed experimentally. The estimation of cracking tendency of mortar ring in early-age is given in a simple ratio defined in

$$
\beta_{\mathrm{CR}}(t)=\frac{\sigma_{\theta-\max }(t)}{f(t)}
$$

in which $\beta_{\mathrm{CR}}(t)$ is termed cracking tendency factor which is the ratio of maximum tensile stress to the split tensile strength of the mortar with respect to age. The maximum tensile stress with respect to age can be determined by the analytical prediction approach present in this paper based on the developing models of hydrate heat, autogenous and drying shrinkage, and creep. The time-dependent modulus and the restraint effects of specimen are vital to the development of the tensile stress and to the stress relaxation effects.

Figure 12 shows the cracking potential for the restraint mortar ring tested in this paper. It can be deduced that the cracking failure will occur when the cracking potential reaches 1 . As the age of the specimen increases, it is commonly accepted that the strength increases or remains constant in conventional mortar. Therefore, if the maximum developed stress level of the mortar is reached and the specimen does not crack, it could be assumed that shrinkage will not cause cracking in the early-age of cementitious materials.

According to Figure 12, the cracking of the restrained mortar ring in the present test will occur at $28 \mathrm{~d}$ after demolding. This prediction of cracking age is quite close to the experimental observation, in which the cracking occurred at $25 \mathrm{~d}$. The predicting error probably results from the accuracy 


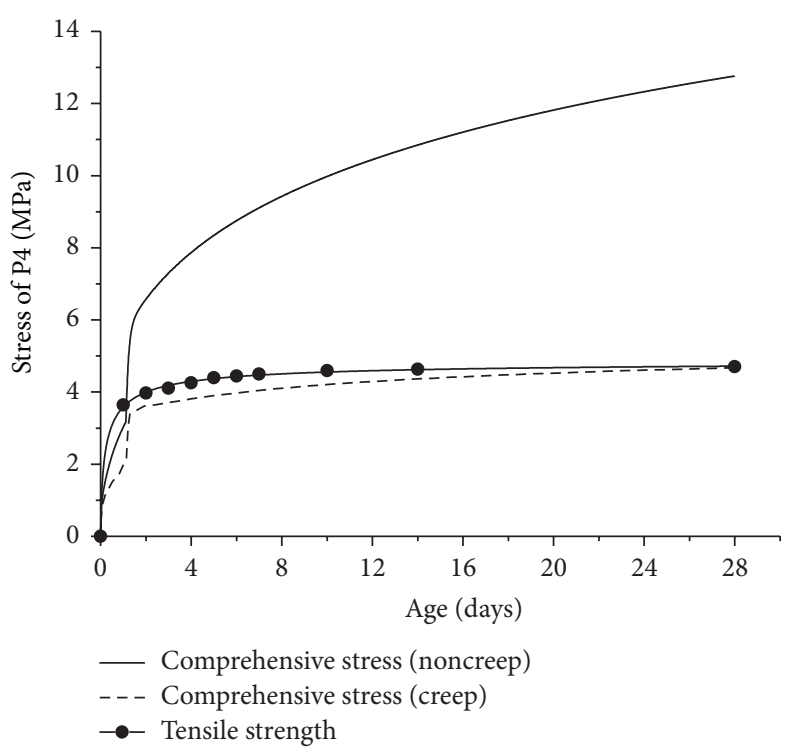

(a)

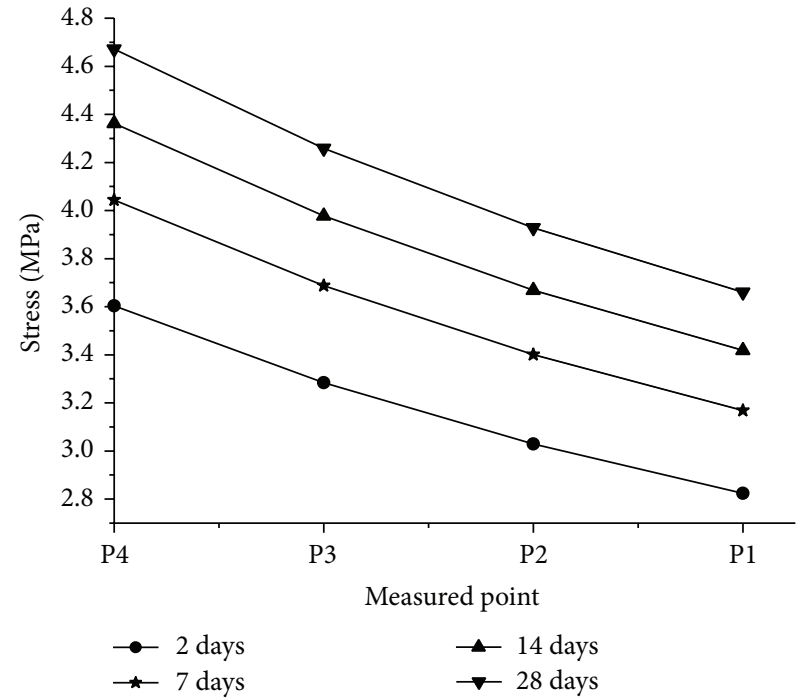

(b)

FIGURE 11: The final comprehensive residual stresses of the restrained mortar ring. (a) Maximum comprehensive residual stresses, at Point 4 of the mortar ring; (b) comprehensive residual stress distribution with age.

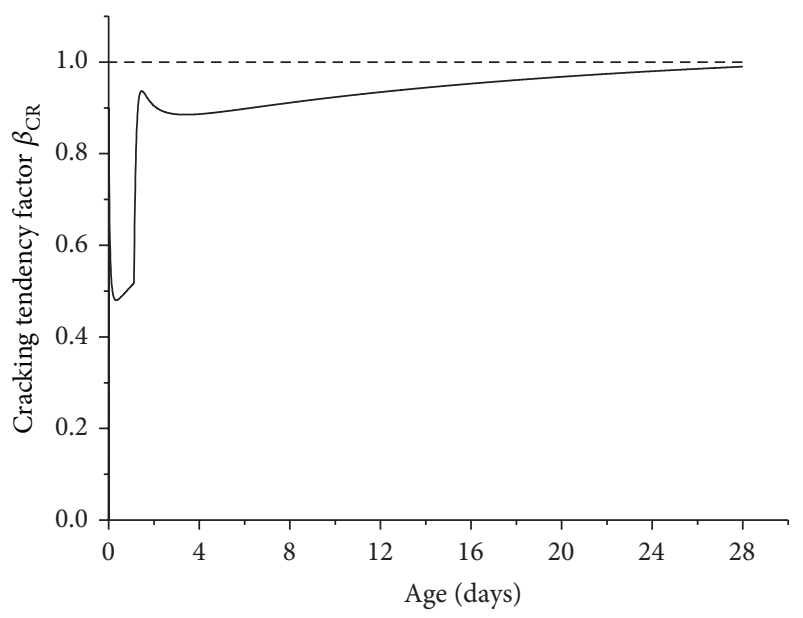

FIGURE 12: Cracking tendency of early-age mortar ring.

of all the related analytical models and the nonuniformity of the properties of the material itself. It is interesting to note that the time-dependent cracking tendency does not appear to vary stably with time. In the first 3 days, the cracking risk increased tremendously which might be caused by the increasing of the stresses due to hydrate heat and autogenous shrinkage and the lower level of mortar strength. Then the cracking risk descended a little and kept in lower level for the next 3 days because of the compatibility between the lager relaxation of the restraint tensile stress and the development of cementitious strength. When the mortar became harder, the creep effects turned to be attenuate, and the developing rate of the residual stress became larger than that of the strength that results in the higher risk of cracking.

\section{Summary and Conclusions}

This paper has developed an analytical approach for calculating stress development and predicting the cracking tendency of the restrained mortar ring under comprehensive driving forces in the early-age. Equations are provided to calculate the actual residual stresses due to hydrate heat, autogenous shrinkage and drying shrinkage, which develop in the ring considering the effects of stress relaxation and compatible deformation of the steel ring. It has also been shown that the analytical predicting of the residual stress development can be carried out once the properties of the materials, such as the strength, especially the tensile strength, the elastic modulus and Poisson ratio, and the environmental parameters, such as RH and temperature, are known. The development of the material properties with time during the early-age can be obtained either by means of test or by the predicting model such as CEB, and so on. A ratio of the predicting maximum residual stress to strength is used to indicate how close a ring may be to failure even if cracking is not observed.

It is concluded that, for the evaluation of the risk of cracking, knowledge of the development of strength and deformability of early-age cementitious materials is extremely important. As mentioned before, the moisture distribution, or termed moisture gradient, is one of the key factors for the distribution and development of residual stresses due to the drying shrinkage. The moisture gradient variation driven by the inner water consumption process due to chemical reaction and the circumstance humidity should be paid more research effort.

In addition, as shown in Figure 4, the mortar ring undergoes large variation in temperature that may result in the expansion and shrinkage of the restrained ring. In order to take into account both the expansion and shrinkage of 
the mixture specimen, Yang and Ma [29] and Scheiner and Hellmich [30] proposed a dual-ring test by which specimen has the ability to consider the restraint of a sample's expansion and the influence of a temperature change on the stress that develops in a concrete mixture. The dual-ring device permits a temperature reduction to be used to assess the remaining stress capacity of a mixture as a method to better assess the resistance of a mixture to early-age cracking. According to their experimental and simulation results, the heating and cooling of the steel ring will affect the restraint stresses of the specimen a great deal. Therefore, in the future research work, either the thermal insensitive material with high elastic modulus for the restrained ring could be used to eliminate the deformation of the ring or the deformation of the steel ring due to the thermal contraction should be taken into account in the simulation of residual stresses to get the more accurate prediction.

More accurate model for the material properties and the mechanisms of autogenous shrinkage which can play a major role in the first few days for high-performance cementitious materials with low w/c ratio also needs research in future. It should be noted that the ratio of residual stress and strength does not appear to be constant at failure considering the nonuniformity and uncertainty of the nature of the materials. This suggests that a failure criterion based solely on single certain strength may be improved.

\section{Conflict of Interests}

The authors declare that there is no conflict of interests regarding the publication of this paper.

\section{Acknowledgments}

The authors gratefully acknowledge the supports received from the Specialized Research Fund for the Doctoral Program of Higher Education for 2012, no. 20120191120056, and the Research Funds for Universities from the Education Ministry in China, nos. CDJZR12245501 and CDJZR200020.

\section{References}

[1] R. W. Burrows, W. F. Kepler, D. Hurcomb, J. Schaffer, and J. G. Sellers, "Three simple tests for selecting low-crack cement," Cement and Concrete Composites, vol. 26, no. 5, pp. 509-519, 2004.

[2] G. De Schutter, "Fundamental study of early age concrete behaviour as a basis for durable concrete structures," Materials and Structures, vol. 35, no. 1, pp. 15-21, 2002.

[3] A. A. Almusallam, "Effect of environmental conditions on the properties of fresh and hardened concrete," Cement and Concrete Composites, vol. 23, no. 4-5, pp. 353-361, 2001.

[4] A. Bentur and K. Kovler, "Evaluation of early age cracking characteristics in cementitious systems," Materials and Structures, vol. 36, no. 257, pp. 183-190, 2003.

[5] E. K. Attiogbe, J. Weiss, and H. T. See, "A look at the rate of stress versus time of cracking relationship observed in the restrained ring test," in Proceedings of the International RILEM Symposium on Advances in Concrete through Science and Engineering, 2004.
[6] J. M. Moon and J. Weiss, "Estimating residual stress in the restrained ring test under circumferential drying," Cement and Concrete Composites, vol. 28, no. 5, pp. 486-496, 2006.

[7] P. Turcry, A. Loukili, K. Haidar, G. Pijaudier-Cabot, and A. Belarbi, "Cracking tendency of self-compacting concrete subjected to restrained Shrinkage: experimental study and modeling," Journal of Materials in Civil Engineering, vol. 18, no. 1, pp. 46-54, 2006.

[8] Z. He and Z. Li, "Influence of alkali on restrained shrinkage behavior of cement-based materials," Cement and Concrete Research, vol. 35, no. 3, pp. 457-463, 2005.

[9] B. Ma, X. Wang, W. Liang, X. Li, and Z. He, "Study on earlyage cracking of cement-based materials with superplasticizers," Construction and Building Materials, vol. 21, no. 11, pp. 20172022, 2007.

[10] J. Weiss, W. Yang, and P. S. Surendra, "Influence of specimen size/geometry on shrinkage cracking of rings," Journal of Engineering Mechanics, vol. 126, no. 1, pp. 93-101, 2000.

[11] W. P. S. Dias, "Influence of mix and environment on plastic shrinkage cracking," Magazine of Concrete Research, vol. 55, no. 4, pp. 385-394, 2003.

[12] A. B. Hossain and J. Weiss, "Assessing residual stress development and stress relaxation in restrained concrete ring specimens," Cement and Concrete Composites, vol. 26, no. 5, pp. 531540, 2004.

[13] Standard Practice for Estimating the Cracking Tendency of Concrete, AASHTO, Washington, DC, USA, 2000.

[14] ASTM C1581-04, Standard Test Method for Determining Age at Cracking and Induced Tensile Stress Characteristics of Mortar and Concrete under Restrained Shrinkage, ASTM International, West Conshohocken, Pa, USA.

[15] O. M. Jensen and P. F. Hansen, "Autogenous deformation and RH-change in perspective," Cement and Concrete Research, vol. 31, no. 12, pp. 1859-1865, 2001.

[16] Y. Yang, R. Sato, and K. Kawai, "Autogenous shrinkage of highstrength concrete containing silica fume under drying at early ages," Cement and Concrete Research, vol. 35, no. 3, pp. 449-456, 2005.

[17] P. Lura, O. M. Jensen, and K. Van Breugel, "Autogenous shrinkage in high-performance cement paste: an evaluation of basic mechanisms," Cement and Concrete Research, vol. 33, no. 2, pp. 223-232, 2003.

[18] B. Kim and W. J. Weiss, "Using acoustic emission to quantify damage in restrained fiber-reinforced cement mortars," Cement and Concrete Research, vol. 33, no. 2, pp. 207-214, 2003.

[19] A. B. Hossain and J. Weiss, "The role of specimen geometry and boundary conditions on stress development and cracking in the restrained ring test," Cement and Concrete Research, vol. 36, no. 1, pp. 189-199, 2006.

[20] J. H. Moon and J. Weiss, "Estimating residual stress in the restrained ring test under circumferential drying," Cement and Concrete Composites, vol. 28, no. 5, pp. 486-496, 2006.

[21] R. W. Carlson, "Drying shrinkage of large concrete members," Journal of the American Concrete Institute, pp. 327-336, 1937.

[22] G. Sant, "The influence of temperature on autogenous volume changes in cementitious materials containing shrinkage reducing admixtures," Cement and Concrete Composites, vol. 34, no. 7, pp. 855-865, 2012.

[23] Z. L. Wang and G. D. Li, "Experimental method and prediction model for autogenous shrinkage of high performance concrete," Construction and Building Materials, vol. 49, pp. 400-406, 2013. 
[24] CEB-FIP Model Code for Concrete Structures, Thomas Telford, Lausanne, Switzerland, 1990.

[25] N. J. Gardner and J. W. Zhao, "Creep and shrinkage revisited," ACI Materials Journal, vol. 90, no. 3, pp. 236-246, 1993.

[26] A. B. Hauggaard, L. Damkilde, and P. Freiesleben Hansen, "Transitional thermal creep of early age concrete," Journal of Engineering Mechanics, vol. 125, no. 4, pp. 458-465, 1999.

[27] ACI Committee, 209-82 Prediction of Creep, Shrinkage and Temperature Effect in Concrete Structure, American Concrete Institute, Detroit, Mich, USA, 1982.

[28] Z. P. Bazant and W. P. Murphy, "Creep and shrinkage prediction model for analysis and design of concrete structures: model B3," Materials and Structures, vol. 28, no. 180, pp. 357-365, 1995.

[29] Q. L. Yang and K. S. Ma, "Analysis of massive concrete 3dimensional finite element hydrated heat temperature field," Journal of Harbin Institute of Technology, vol. 36, no. 2, pp. 261263, 2004 (Chinese).

[30] S. Scheiner and C. Hellmich, "Continuum microviscoelasticity model for aging basic creep of early-age concrete," Journal of Engineering Mechanics, vol. 135, no. 4, pp. 307-323, 2009. 

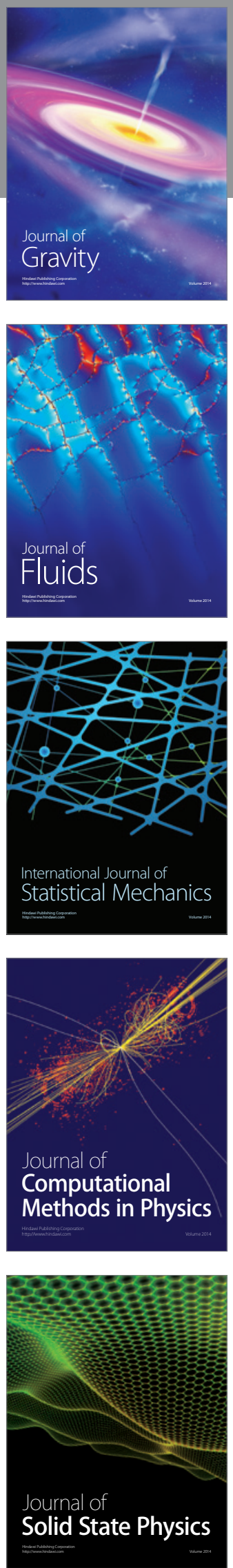

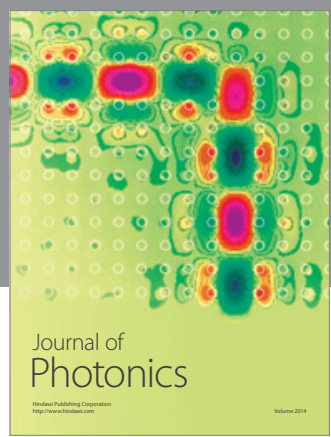

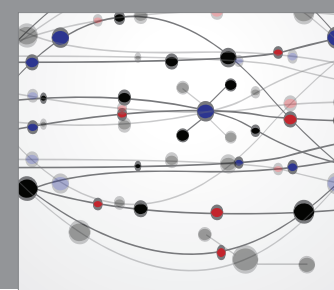

The Scientific World Journal

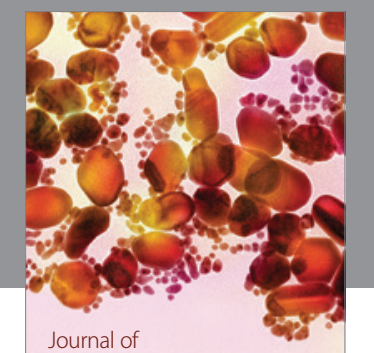

Soft Matter
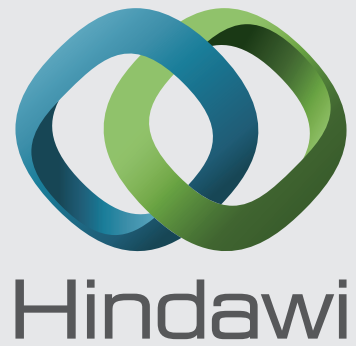

Submit your manuscripts at

http://www.hindawi.com
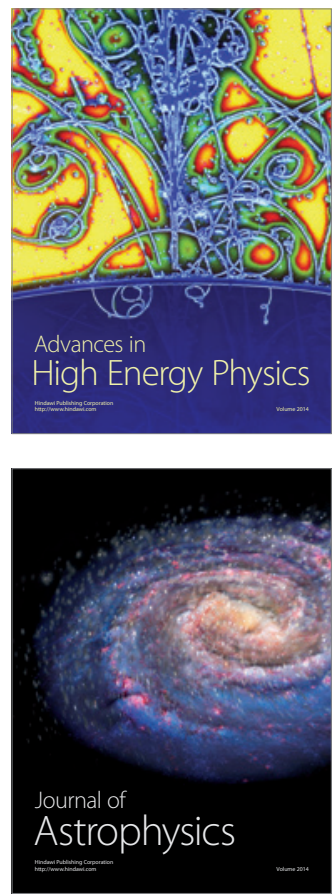
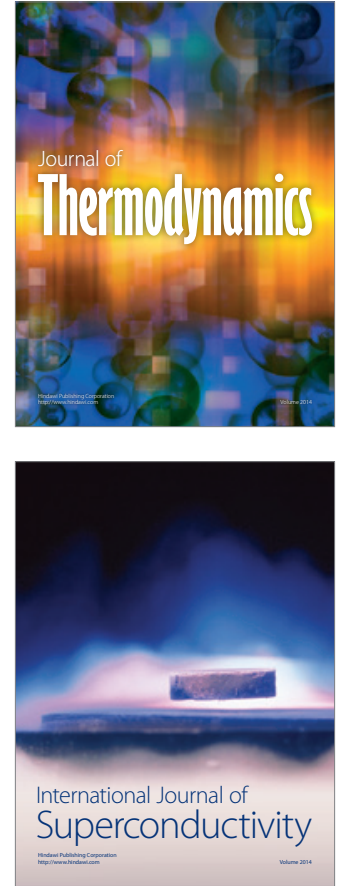
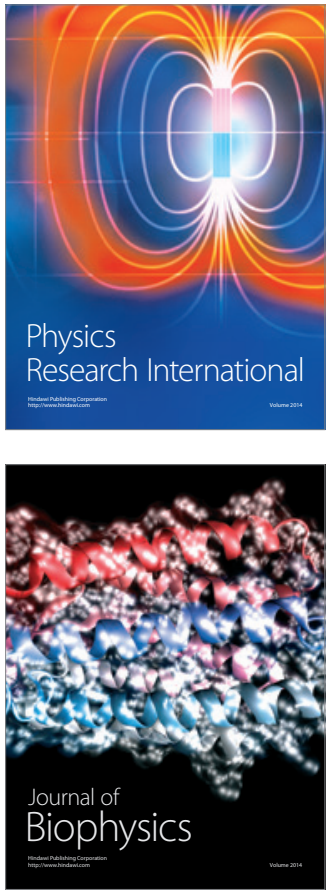
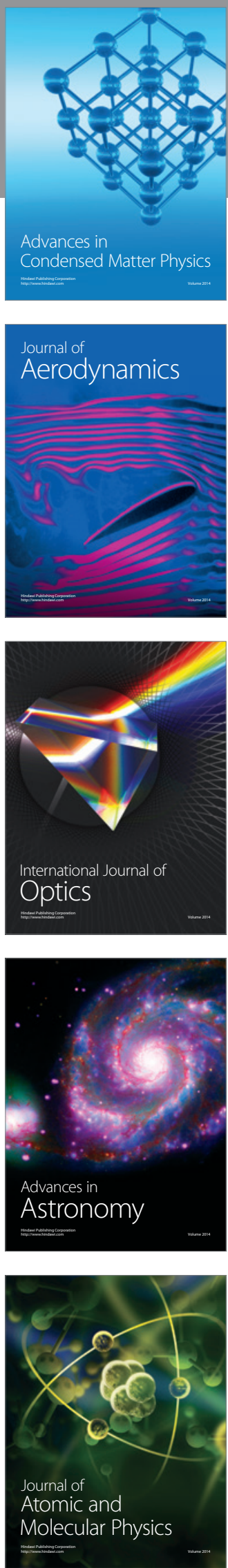